\title{
Risk Factors for Mortality of Newborn at Kolwezi Hospital
}

\author{
Kabamba Nzaji Michel1, Mindje Kolomba Bertin², Kalonji Tshibwabwa Deddy³, \\ Kilolo Ngoy Umba Elie ${ }^{4}$, Kwete Botshiabo Jack ${ }^{5}$, Yowa Malemba Yvette ${ }^{5}$, \\ Kabwe Matanda Pascal6, Nday Mwadiavita Charles7, Oscar Luboya Numbi ${ }^{8}$ \\ ${ }^{1}$ Department of Public Health, Faculty of Medicine, University of Kamina, Kamina, Democratic Republic of Congo \\ ${ }^{2}$ General Hospital of Reference Kamina, Kamina, Democratic Republic of Congo \\ ${ }^{3}$ Department of Pediatrics, Faculty of Medicine, University of Kamina, Kamina, Democratic Republic of Congo \\ ${ }^{4}$ Department of Obstetrics and Gynecology, Faculty of Medicine, University of Kamina, Kamina, \\ Democratic Republic of Congo \\ ${ }^{5}$ Department of Obstetrics and Gynecology, Faculty of Medicine, University of Kolwezi, Kolwezi, \\ Democratic Republic of Congo \\ ${ }^{6}$ Nursing Sciences, Higher Institute of Medical Techniques of Lubumbashi, Lubumbashi, Democratic Republic of \\ Congo \\ ${ }^{7}$ Nursing Sciences, Higher Institute of Medical Techniques of Kamina, Kamina, Democratic Republic of Congo \\ ${ }^{8}$ Department of Public Health and Paediatrics, Faculty of Medicine, University of Lubumbashi, Lubumbashi, \\ Democratic Republic of Congo \\ Email: michelnzaji@yahoo.fr
}

Received 23 June 2016; accepted 14 August 2016; published 19 August 2016

Copyright (C) 2016 by authors and OALib.

This work is licensed under the Creative Commons Attribution International License (CC BY). http://creativecommons.org/licenses/by/4.0/

(c) (i) Open Access

\section{Abstract}

The WHO estimates that about 130 million children born each year worldwide, and about 4 million die during the neonatal period. Neonatal mortality remains until now a major public health problem in the world and is the socio-economic indicators of progress and health of a country by its frequency. This study aimed to identify risk factors of neonatal mortality through maternal and new-born characteristics susceptible to influence this last. We conducted a longitudinal study from January 1st to December 2014 based on data collected through a questionnaire developed for this purpose. This questionnaire was tested, standardized and administered in the maternity and neonatology service in the language spoken by the mother (Swahili or French). Results: Anemia and neonatal asphyxia were significantly associated with the occurrence of death with adjusted odds ratio of 34.570 respectively (CI: 5.633 to 212.149 , 95\%) and 7861 (CI: 2.017 to 30.644 ). The history of fetal deaths and HIV in mothers was also recognized as an explanatory factor for the occurrence of neonatal mortality. But it should be noted that the CPN followed and the history of genital bleeding in the first trimester of pregnancy have made protective factors for developing neonatal mortality with their respective adjusted OR of 0.169 (CI: 0.037 to $0.775,95 \%$ ) and 0.066 (CI: 0.005 to 0.906). Conclusion: To address this problem, the management of various risk factors

How to cite this paper: Michel, K.N., Bertin, M.K., Deddy, K.T., Elie, K.N.U., Jack, K.B., Yvette, Y.M., Pascal, K.M., Charles, N.M. and Numbi, O.L. (2016) Risk Factors for Mortality of Newborn at Kolwezi Hospital. Open Access Library Journal, 3: e2849. http://dx.doi.org/10.4236/oalib.1102849 


\title{
that may influence the occurrence of neonatal mortality should be taken into account.
}

\section{Keywords}

\author{
Risk Factor, Mortality, Neonatal, Kolwezi
}

Subject Areas: Pediatrics, Public Health

\section{Introduction}

Neonatal mortality remains until now a major public health problem in the world; it is the socio-economic indicators of progress and health of a country and represents over $60 \%$ of deaths of infants before their first anniversary [1]. It is defined as deaths occurring between 0 and 28 days of life. It consists of early neonatal deaths where the death occurs during the first seven days of life, and late neonatal mortality expressing the occurrence of death from the 8th to 27th day of life. In 2005, the World Health Organization (WHO) estimated that over 130 million children born each year worldwide, and about 4 million die in the neonatal period [2]. In industrialized countries, child deaths became rare today. Africa has the highest rate of the neonatal mortality estimated at 45 deaths per 1000 live births against 5 deaths in developed countries [1]. In this continent, mortality of newborns remains relatively high. This sparked a research interest in many African researchers who had addressed the underlying factors to the high mortality of children in Sub-Saharan Africa [3]. The Democratic Republic of Congo ranked among the countries with the highest number of neonatal deaths in the world with 116 neonatal deaths in thousands, $3 \%$ of neonatal deaths globally and $47 \%$ of neonatal mortality rate per 1000 live births [4].

In view of the frightening statistics of mortality in the world, in Africa in general, DR Congo, and in particular Kolwezi and especially no published data on in-hospital neonatal mortality in our environment has been published this day. The purpose of this study was to determine the risk factors for neonatal mortality in KHP to improve the monitoring of pregnant women and provide better care for newborns.

\section{Material and Methods}

A longitudinal study with analysis of neonatal mortality risk factors was conducted in the service of maternity and neonatology of the Hospital Staff Kolwezi in Katanga Province in the Democratic Republic of Congo. The study population consists of torque newborn mothers born during the study period, from January 1 to December 2014. Newborns with incomplete records and whose mother does not cooperate were excluded from the study. Sampling was exhaustive. Hospital records of these are the data sources. By exploiting these records, the following information was collected: the outcome of neonates at day 28 and the health profile of mothers.

The data is processed and analyzed using the Epi-Info software; we used logistic regression models. The association of certain variables with mortality was measured with the Relative Risk (RR) and its confidence interval of $95 \%$ was given. The chi square test was used for comparison of proportions. The significance level was set at 0.05 .

This study was approved by related ethics committee besides and mothers sign informed consent and have a whole understanding of this study. Our study had no binding character. Any information collected from mothers has been and will remain confidential. Similarly, the names of participants will remain confidential and will not be mentioned in the presentation of results or associated to results in any way whatsoever. They will also be disclosed to any third party.

\section{Results}

Table 1 shows that a total of 149 infants were included in this study, 28 or $18.8 \%$ died before the 28th day of life (neonatal mortality). The boys represent $56.4 \%$ with a sex ratio of 1.27 . The low birth weight was significantly associated with the occurrence of death $(\mathrm{OR}=2.61)$.

Table 2 shows that the proportion of deaths is 4.4 times higher when the mother does not follow the CPN (OR $=$ 4.44). In the light of history, mothers who have had genital bleeding in the first quarter have 5 times the risk neonatal death $(\mathrm{OR}=5.347)$ and 2.7 times the risk of death for women with newborns submitted to artificial feeding or mixed $(\mathrm{OR}=2740)$, the history of fetal death also was significantly associated with the occurrence of death. 
Table 1. Proportion of deaths according to the characteristics of newborns.

\begin{tabular}{|c|c|c|c|c|}
\hline Characteristics of Newborns & Death (\%) & Heal (\%) & OR [95\%] & $\mathrm{p}$ \\
\hline \multicolumn{5}{|l|}{ Kind } \\
\hline Male & $16(19.0)$ & $68(81.0)$ & $0.962[0.420-2.207]$ & 0.928 \\
\hline Female & $12(18.5)$ & $53(81.5)$ & & \\
\hline \multicolumn{5}{|l|}{ Birth Weight } \\
\hline FPN & $12(30.8)$ & $27(69.2)$ & $2.611[1.103-6.184]$ & 0.026 \\
\hline PN & $16(14.5)$ & 94 (85.5) & & \\
\hline \multicolumn{5}{|l|}{ APGAR } \\
\hline$<7$ & $6(27.3)$ & $16(72.7)$ & $1.790[0.630-5.088]$ & 0.270 \\
\hline$>7$ & $22(17.3)$ & $105(82.7)$ & & \\
\hline \multicolumn{5}{|l|}{ Anemia } \\
\hline No & $21(15.2)$ & $117(84.8)$ & $0.103[0.028-0.381]$ & 0.000 \\
\hline Yes & $7(63.6)$ & $4(36.4)$ & & \\
\hline \multicolumn{5}{|l|}{ Neonatal infection } \\
\hline No & $8(15.4)$ & $84(84.6)$ & $0.700[0.285-1.721]$ & 0.436 \\
\hline Yes & $20(20.6)$ & $77(79.4)$ & & \\
\hline \multicolumn{5}{|l|}{ Asphyxia } \\
\hline No & $21(15.8)$ & $112(84.2)$ & $0.241[0.081-0.719]$ & 0.007 \\
\hline Yes & $7(43.8)$ & $9(56.3)$ & & \\
\hline \multicolumn{5}{|l|}{ Hypoglycemia } \\
\hline No & $26(18.3)$ & $116(81.7)$ & $0.560[0.103-3.049]$ & 0.497 \\
\hline Yes & $2(28.6)$ & $5(71.4)$ & & \\
\hline \multicolumn{5}{|l|}{ Icterus } \\
\hline No & $25(20.3)$ & 98 (79.7) & $1.956[0.543-7.040]$ & 0.297 \\
\hline Yes & 3 (11.5) & $23(88.5)$ & & \\
\hline
\end{tabular}

Table 2. Proportion of deaths based on maternal history.

\begin{tabular}{|c|c|c|c|c|}
\hline Characteristics of Newborns & Death (\%) & Heal (\%) & OR $[95 \%]$ & $\mathrm{p}$ \\
\hline \multicolumn{5}{|l|}{ Parity } \\
\hline Multipare & $20(19.6)$ & $82(80.4$ & $1.189[0.481-2.937]$ & 0.707 \\
\hline Primipare & $8(17.0)$ & 39 (83.0) & & \\
\hline \multicolumn{5}{|l|}{ Gravidity } \\
\hline Multigravida & $22(19.8)$ & $89(80.2)$ & $1.318[0.490-3.544]$ & 0.583 \\
\hline grAvida & $6(15.8)$ & $32(84.2)$ & & \\
\hline \multicolumn{5}{|l|}{ Inter-reproductive area } \\
\hline$\leq 1$ year & $12(21.1)$ & 45 (78.9) & $1.267[0.55-2.918]$ & 0.578 \\
\hline$\geq 2$ years & $16(17.4)$ & 76 (82.6) & & \\
\hline
\end{tabular}




\section{Continued}

History of fetal death

No

Yes

Monitoring the CPN

No

Yes

Number of CPN followed

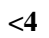

$\geq 4$

History of genital bleeding in the first quarter

\section{No}

Yes

Time between the rupture of the amniotic sac and birth

$$
\leq 2: 00
$$$$
>2 \text { hours }
$$

Type breastfeeding

Artificial or mixed

Exclusive in
6 (46.2)

$22(16.2)$

17 (23.9)

$11(14.1)$

$19(15.2)$

106 (84.8)

$0.299[0,114-0,780]$

0.010

$15(62.5)$

7 (53.8)

$4.442[1.362-14.485]$

0.008

114 (83.8)

54 (76.1)

1.918 [0.829 - 4.437]

0.125

67 (85.9)

27 (21.1)

101 (78.9)

5.347 [0.686 - 41.646]

0.076

1 (4.8)

20 (95.2)

22 (19.0)

94 (81.0)

$1.053[0.388-2.860]$

0.919

6 (18.2)

27 (81.8)

12 (31.6)

$26(68.4)$

$2.740[1,154$ - 6,509]

0.019

Table 3 showed that HIV was significantly associated with the occurrence of death. No significant association with maternal diseases such as premature rupture of membranes, placenta previa, preeclampsia or eclampsia, malaria and urogenital infections were observed.

Table 4 shows that anemia and neonatal asphyxia were significantly associated with the occurrence of death with adjusted odds ratio of 34.570 respectively (CI: 5.633 to 212.149 , 95\%) and 7.861 (CI: 2.017 to 30.644 ). The fetal deaths and HIV in mothers were also recognized as an explanatory factor for the occurrence of neonatal mortality. But it should be noted that the CPN followed and the history of genital bleeding in the first quarter during pregnancy constituted protective factors for developing neonatal mortality because their adjusted OR are respectively 0.169 (CI: 0.037 to $0.775,95 \%)$ and 0.066 (CI: 0.005 to 0.906$)$.

\section{Discussion}

This study concerns newborns treated in the maternity of the Kolwezi Staff Hospital. Thus, the results remain valid for part of the study and do not reflect the situation in the general population. They will provide reference data for future studies.

According to the results of this study, the impact of neonatal mortality was $18.8 \%$. This rate is lower than 20.3\% found by Danielle Christiane Kedy Kum et al. Douala [5], 22.7\% in Madagascar [6] and significantly higher than $1.74 \%$ by Nsagha found in Nkongsamba in Cameroon [7]. This rate sometimes higher and lower in our study could be explained by a very low ratio of staff to patient HPK one hand and on the other hand, denotes the importance of antenatal and perinatal factors and the mastery of neonatal resuscitation and good management that would reduce this mortality rate.

Regarding the newborn, low birth weight was significantly associated with the occurrence of death (OR = 2.61). In our series newborns had 2.6 times the risk of dying against six times compared to normal-weight newborns. This result is consistent with those of the literature [8]. According to the results of a study in the University Hospital of Dakar, a proportion of deaths of $80.3 \%$ is observed for the newborns weighing less than $1500 \mathrm{~g}$, $33.2 \%$ between $1500 \mathrm{~g}$ and $2500 \mathrm{~g}$ and $13 \%$ for new-borns of greater than $2500 \mathrm{~g}$ weight [9]. This supports the 
Table 3. Proportion of deaths to pathologies during pregnancy.

\begin{tabular}{|c|c|c|c|c|}
\hline Pathologies & Death (\%) & Heal (\%) & OR [95\%] & $\mathbf{p}$ \\
\hline \multicolumn{5}{|c|}{ Premature rupture membranes } \\
\hline No & $27(18.4)$ & $120(81.6)$ & $0.225[0.014-3.711]$ & 0.255 \\
\hline Yes & $1(50.0)$ & $1(50.0)$ & & \\
\hline \multicolumn{5}{|c|}{ Preeclampsia or eclampsia } \\
\hline No & 26 (19.5) & $107(80.5)$ & $1.701[0.364-7.953]$ & 0.495 \\
\hline Yes & $2(12.5)$ & $14(87.5)$ & & \\
\hline \multicolumn{5}{|l|}{ Placenta previa } \\
\hline No & 27 (18.9) & $116(81.1)$ & $1.164[0.131-10.37]$ & 0.892 \\
\hline Yes & $1(16.7)$ & $5(83.3)$ & & \\
\hline \multicolumn{5}{|c|}{ Urogenital infection } \\
\hline No & $8(13.6)$ & $51(86.4)$ & $0.549[0.224-1.345]$ & 0.186 \\
\hline Yes & $20(22.2)$ & $70(77.8)$ & & \\
\hline \multicolumn{5}{|l|}{ HIV } \\
\hline No & $24(16.7)$ & $120(83.3)$ & $0.050[0.05-0.467]$ & 0.000 \\
\hline Yes & $4(80.0)$ & $1(20.0)$ & & \\
\hline \multicolumn{5}{|l|}{ Malaria } \\
\hline No & $16(21.6)$ & $58(78.4)$ & $1.448[0.632-3.318]$ & 0.380 \\
\hline Yes & $12(16.0)$ & $63(84.0)$ & & \\
\hline
\end{tabular}

Table 4. Logistic regression of various predictors of neonatal mortality.

\begin{tabular}{|c|c|c|c|c|c|c|c|}
\hline \multirow{2}{*}{ Neonatal deaths of explanatory factors } & \multirow{2}{*}{$\mathrm{AT}$} & \multirow{2}{*}{ E. S. } & \multirow{2}{*}{ Wald } & \multirow{2}{*}{$\mathrm{p}$} & \multirow{2}{*}{$\operatorname{Exp}(\mathrm{B})$} & \multicolumn{2}{|c|}{ CI for $\operatorname{Exp}(B) 95 \%$} \\
\hline & & & & & & Inferior & Superior \\
\hline Anemia & 3.543 & 926 & 14.650 & 0.000 & 34.570 & 5.633 & 212.149 \\
\hline Asphyxia & 2.062 & 694 & 8.824 & 0.003 & 7861 & 2.017 & 30.644 \\
\hline CPN followed & -1.780 & 778 & 5.236 & 0.022 & 0.169 & 0.037 & 0.775 \\
\hline History of genital bleeding in the first quarter & -2.713 & 1334 & 4.135 & 0.042 & 0.066 & 0.005 & 0.906 \\
\hline History of fetal death & 1.629 & 628 & 6.731 & 0.009 & 5.099 & 1.489 & 17.455 \\
\hline HIV & 3.657 & 1223 & 8.945 & 0.003 & 38.739 & 3.527 & 425.497 \\
\hline Constant & -5.428 & 2121 & 6.550 & 0.010 & 0.004 & & \\
\hline
\end{tabular}

Legend: A: regression coefficient; E. S.: standard error of the regression coefficient; Wald: Wald test; p: p-value adjusted; Exp (B): adjusted odds ratio, CI: confidence interval Exp (B).

hypothesis that infants with low birth weight are at risk of neonatal death 40 times higher than babies of normal weight and risk of post-neonatal death 5 times higher. This is explained by the fact that low birth weight is due to short gestation (premature birth) or growth restriction in utero or both. These infants are highly vulnerable to infections and incomplete immunity.

Given that neonatal asphyxia was significantly associated with death in our series $43.8 \% \mathrm{p}=0.007$. Our results corroborate with those of Diallo et al. [10] According to these, fetal distress was the second cause of death after premature birth with $30.80 \%$ of deaths. This same finding was observed by Cissé et al. in Mali in 2010 [9] 
$84 \%$ of deaths among infants in the study were due to fetal distress. But note that no significant association was reported between gender, infection and Apgar score. But this is disputed by several studies in the world, is the case of Susana de Paula et al. in Brazil in 2010, an Apgar score below 7 at the end of the 5th minute is coupled to a higher mortality rate in general [11]. Considering neonatal infection while not significantly related to the occurrence of death in our study According Agbère et al, neonatal infection is the leading cause of death of the newborn in Togo [12]. This is justified by the fact that infectious diseases often due to three seeds in neonatology: Streptococcus beta hemolytic group B, Listeria monocytogenes and Escherichia coli play a major role in the deaths of infants early and late new-born deaths, and this advantage in our poor and middle where the neonatal mortality rate is high. Thus, interventions designed to prevent and treat these diseases in newborns (e.g. Quick Start breastfeeding, availability of antibiotics) can be used with some adjustments in favor of the latter. However, newborns also die of other causes as infections, especially during the first week of life. Overall, the direct causes of neonatal mortality in our series are: anemia (63.6\%), hypoglycemia (28.6\%), jaundice (20.3\%) and respiratory distress $(18,9 \%)$. This could be explained by fragile newborns, can succumb to the slightest infection and also cause severe disability and life among infants who survive.

The proportion of deaths is 4.4 times higher when the mother does not follow the CPN (OR $=4.44)$ and the number of CPN followed $<4$ is $23.9 \%$. Failure to follow or irregular CPP promote neonatal mortality in our study on the effect of the CPN on neonatal deaths, according to WHO, prenatal care are used for detection of problems during pregnancy and also to prepare childbirth. These preventive measures are intended to make the optimal course and outcome of pregnancy [13]. In terms of prenatal monitoring, several authors have found that the number of ANC below 3 is associated with low birth weight and. This phenomenon can be explained by the fact that the lack of monitoring of pregnancy is not allowed to act on the medical causes of neonatal death treatable or to monitor the results of systematic preventive measures against malaria, anemia or nutritional deficiencies. Mohammad et al., cited by Daniella revealed that the defective monitoring of pregnancies is one of the causes of frequent deaths [5]. In this study $40 \%$ of patients did not complete at least 4 EIC. This reinforces the need for awareness of community women about the importance of ANC. This demonstrates the importance of monitoring of pregnancy, the parameters and interventions are crucial to a harmonious growth and survival of the newborn. These results suggest to strengthen the monitoring of pregnancy by improving EIC for timely detection of high risk pregnancies and ultimately a decrease in neonatal mortality.

Considering the history, mothers who have had genital bleeding in the first quarter have five times the risk neonatal death $(\mathrm{OR}=5.347)$ and 2.7 times the risk of death for women with newborns submitted to artificial feeding or mixed (OR $=2.740)$, the history of fetal death also was significantly associated with the occurrence of death. No significant association with parity, gravidity, the time between the rupture of the amniotic sac and birth is observed. We may associate the bleeding and fetal death following maternal infectious diseases (malaria infection and urogenital), which unfortunately is not the risk of mortality in our study. This is explained on the occasion of malaria, the bursting of the red blood cell parasitized causes the release of malarial pigment (hemozoin) that acts as a pyrogenic substance to the toxin released in case of occurrence of infections bacterial or parasitic, acting on the bulbar center of thermoregulation causing hyperthermia. Hyperthermia acts on the hypothalamus that will synthesize and release oxytocin which causes uterine contractions which are the basis of premature birth, abortion, fetal death and IUGR with low birth weight is the cause of perinatal morbidity and mortality [14]. As for the artificial feeding the mixed, it's a hygiene problem and faulty preparation is lacking and introduces the germs in a being vulnerable to the death of the immunity by default.

The inter birth interval of one year is $21.1 \%$, although it is a risk factor in our study, several findings show that many and too close maternity greatly increase the risk of anemia, but also deficits nutritional maternal and postpartum stress that will result in neonatal mortality. Health risks resulting from poor spacing resulting in pregnancies too close together and too many are well established as in the Mediterranean region [15]. Hence the importance of promoting family planning among married women is an effective intervention to prevent avoidable morbidity and mortality in children, including newborns and their mothers in Kolwezi.

Our study shows that HIV was significantly associated with the occurrence of death, no significant association with the maternal conditions such as premature rupture of membranes, placenta previa, preeclampsia or eclampsia, malaria and urogenital infections $\mathrm{n}$ is observed. Infectious diseases during pregnancy compared to the severe outcome, their impact on health and neonatal mortality are well documented. These include syphilis, malaria, HIV/AIDS, toxoplasmosis, rubella, cytomegalovirus and herpes simplex, and these diseases increase the likelihood of maternal anemia, of spontaneous abortion, stillbirth, prematurity, intrauterine growth retardation 
and low birth weight of the newborn and mortality. But we found in our study that premature rupture of membranes is $50.0 \%$, a figure well above $20.4 \%$ found in the Mediterranean region [2]. We also noted cases of prolonged labor, sub partu fevers treated as malaria. The difference between the figures, they increase the risk of prematurity, neonatal infection, neonatal d'asphyxie and neonatal mortality as demonstrated above.

Multivariate logistic regression analysis shows that anemia and neonatal asphyxia were significantly associated with the occurrence of death with adjusted odds ratio of 34.570 respectively (CI: 5.633 to 212.149 , 95\%) and 7.861 (CI: 2.017 to 30.644). The fetal deaths and HIV in mothers were also recognized as an explanatory factor for the occurrence of neonatal mortality. But it should be noted that the CPN not followed and the history of genital bleeding in the first quarter during pregnancy constituted protective factors for developing neonatal mortality because their adjusted OR are respectively 0.169 (CI: 0.037 to $0.775,95 \%$ ) and 0.066 (CI: 0.005 to 0.906). One factor has been found by other authors in Cameroon, Mali, in the Mediterranean region and Brazil [2] [5].

\section{Conclusions}

This study, which helped establish the risk factors of neonatal mortality in KHP, showed that six factors influenced neonatal mortality by logistic regression namely anemia, asphyxia, no followed CPN, the antecedent of bleeding in the first quarter of pregnancy, previous fetal deaths and HIV were factors behind the occurrence of neonatal mortality. The followed CPN and the genital bleeding history in the first quarter during pregnancy were protective factors for developing neonatal mortality. These six factors were either due to the lack of adequate equipments and qualified personals or to the lack of antenatal care of quality and information to pregnant women.

The initiation of an action plan targeting the different factors in pregnant women and newborns explaining neonatal mortality is required. Thus, special attention should be given by health staff (gynecologist and obstetrician, neonatologist and nurse pediatrics) to these factors to reduce the risk of neonatal mortality and contribute to reducing this public health problem in our community.

To decrease the neonatal mortality, the government must equip hospitals with adequate materials; continually train nurses and doctors in charge of newborn; make free antenatal consultation (ANC) and risk factors of newborn mortality must be informed to pregnant women.

\section{Author Contributions}

All authors contributed to writing this article, have read and approved the final version.

\section{References}

[1] Ezeh, O.K., Agho1, K.E., Dibley, M.J., Hall, J. and Page, A.N. (2015) Determinants of Neonatal Mortality in Nigeria: Evidence from the 2008 Demographic and Health Survey. BMC Public Health, 14, 521. http://dx.doi.org/10.1186/1471-2458-14-521

[2] Raobijaona, H. and Rakotomanga, J. (2015) Determinants of Early Neonatal Mortality in Maternity Befelatanana, Antananarivo. Revue d'Anesthésie-Réanimation et de Médecine d'Urgence, 6, 1-4. http://www.rarmu.com/publications/6(1)/full_text/6(1)_1-4.pdf

[3] Lasme, E. and Charles, J. (2013) Determinants of Mortality in Children under Five in Ivory Coast. European Scientific Journal, 9, 139-150.

[4] WHO (2007) Neonatal Mortality in the Eastern Mediterranean Region: Determinants and Strategies for Achieving the Fourth Millennium Development.

[5] Koum, D.C.K., Essomba, N.E., Ngaba, G.P., Sintat, S., Ndombo, P.K. and Coppieters, Y. (2015) Morbidité et facteurs de risque de mortalité néonatale dans un hôpital de référence de Douala. The Pan AfricanMedical Journal, 20, 258.

[6] Randrianjafinimpanana, H., Ratsimandresy, R. and Ratsitohaina, H. (2008) Les facteurs de risque de mortalité néonatale au CHU Mère Enfant Tsaralalana-H, 55.

[7] Nsagha, S.D., Assob, N.J.C., Kamga, F.H.L., Njunda, L.A., Nde, P.F., Mpei, E. and NNjouendou, A.J.N.N. (2014) Facteurs Influençant la mortalité au service de pédiatrie de l’hopital régional de Nkongsamba au cameroun. AJIH, 3, 38-45.

[8] Haon, P.T., Bao, T.V., Phong, D.N., Huong, N.T. and Lazare, M.B.M. (2000) Mortalité néonatale précoce à l’Hopital de gynécologie-obstétrique de Hanoi, Vietnam. Bull Soc Pathol Exot., 93, 62-65. 
[9] Cissé, C.T., Yacoubou, Y., Ndiaye, O., Diop-Mbengue, R. and Moreau, J.-C. (2010) Évolution de la mortalité néonatale précoce entre 1994 et 2003 au CHU de Dakar. Reproduction, Journal de Gynécologie Obstétrique et Biologie de la, 20, 4.

[10] Diallo, S., Kourouma, S.T. and Camara, Y.B. (1998) Mortalité néonatale à l’Institut de nutrition et de santé de l'enfant (INSE). Méd d'Afrique Noire, 45, 4-7.

[11] Risso, S. and Nascimento, L. (2010) Risk Factors for Neonatal Death in Neonatal Intensive Care Unit Selon Survival Analysis. Revista Brasileira de Terapia Intensiva, 22, 19-26. http://www.scielo.br/scielo.php?pid=S0103-507X2010000100005\&script=sci arttext

[12] Agbere, A.D., Balaka, B., Baeta, S., Douti, Y., Atakouma, D.Y., Kessie, K., et al. (1998). Mortalité néonatale dans le service de pédiatrie du centre hospitalier régional de Sokode (Togo) en 1984-1985 et 1994-1995. Med Afr Noire., 45, 5-7.

[13] UNICEF, WHO (2013) Levels and Trends in Child Mortality.

[14] Blondel, B., Eb, M., Matet, N., Bréart, G. and Jougla, E. (2005) Neonatal Mortality in France: Assessment and Intake of Neonatal Death Certificate. Pediatric Archives, 12, 1448-1455. http://dx.doi.org/10.1016/j.arcped.2005.05.009

[15] de Araújo, B.F., Tanaka, A.C.d’A., Madi, J.M. and Zatti, H. (2005) Estudo da mortalidade de recémnascidos internados na UTI neonatal do Hospital Geral de Caxias do Sul, Rio Grande do Sul. Revista Brasileira de Saúde Materno Infantil, 5, 463-469.

\section{Submit or recommend next manuscript to OALib Journal and we will provide best service for you:}

- Publication frequency: Monthly

- 9 subject areas of science, technology and medicine

- Fair and rigorous peer-review system

- Fast publication process

- Article promotion in various social networking sites (LinkedIn, Facebook, Twitter, etc.)

- Maximum dissemination of your research work

Submit Your Paper Online: Click Here to Submit

Contact Us: service@oalib.com 